\title{
Multiple skin metastases in a patient with acute myelomonocytic leukemia
}

\author{
Daye Munise', Temiz Selami Aykut', Oltulu Pembe ${ }^{2}$
}

\author{
${ }^{1}$ Necmettin Erbakan Univercity Meram Faculty of Medicine, Department of Dermatology ${ }^{2}$ Necmettin Erbakan Univercity \\ Meram Faculty of Medicine, Department of Pathology
}

Corresponding author: Dr. Temiz Selami Aykut, E-mail: aykutmd42@gmail.com

\begin{abstract}
Metastatic skin tumors may occur before or at any time before the diagnosis of malignancy. Skin metastases are thought to be indicative of advanced stage malignancy or non-treatment response. Cutaneous metastases are a worse prognostic mark, especially in patients with cancer of the lung, ovary, upper respiratory tract, or upper digestive tract. Acute myelomonocytic leukemia is a malignant-hematopoietic clonal sickness of bone marrow and disrupts production of normal blood cells. Although there are many and various dermatological findings in acute leukemia, they are mostly due to cytopenia and haemostasis disorders and skin metastasis is not frequent. Here, we present a case of skin involvement with a diagnosis of acute myelomonocytic leukemia, which is uncommon in the literature and nodules on the whole body.
\end{abstract}

Key words: Acute leukemia; Acute myelomonocytic leukemia; Skin metastas

\section{INTRODUCTION}

Metastatic skin tumors may occur before or at any time before the diagnosis of malignancy [1]. Skin metastases are thought to be indicative of advanced stage malignancy or non-treatment response [2]. Cutaneous metastases are a worse prognostic mark, especially in patients with cancer of the lung, ovary, upper respiratory tract, or upper digestive tract [3].

Acute myelomonocytic leukemia (AML M4) is a malignant-hematopoietic clonal sickness of bone marrow and disrupts production of normal blood cells [4]. Although there are many and various dermatological findings in AML, they are mostly due to cytopenia and haemostasis disorders and skin metastasis is not frequent [5].

Here, we present a case of skin involvement with a diagnosis of AML M4, which is uncommon in the literature and nodules on the whole body.

\section{CASE REPORT}

A 19-year-old woman was referred from the hematology polyclinic to the dermatology polyclinic because of the multiple purple nodular lesions on the skin. Dermatologic examination revealed purple colored infiltrative nodular lesions in the trunk and extremities (Fig. 1). It was identified that the lesions of the case developed within one month and covered the whole body. It was learned that the case was followed up with AML M4 diagnosis. In the laboratory review; WBC: 30,9/ul Neu: 1,48/ul Monocyt: 23,8/ul Hgb: 10,5 g/dL Plt: 35,4/uL LDH: 1333 U/L CRP: 201,7 mg/L.

In terms of differential diagnosis, skin biopsies were taken with preliminary diagnosis (AML skin metastasis, lichenoid drug reaction, papular mucinosis, B cell lymphoma). Histopathologic examination, diffuse tumor infiltration in the dermis, strong CD33 (+) in the tumor cells due to weak CD117 and CD4 $(+)$; myeloid originated (especially M4) leukemia infiltration (Figs. 2A-2E).

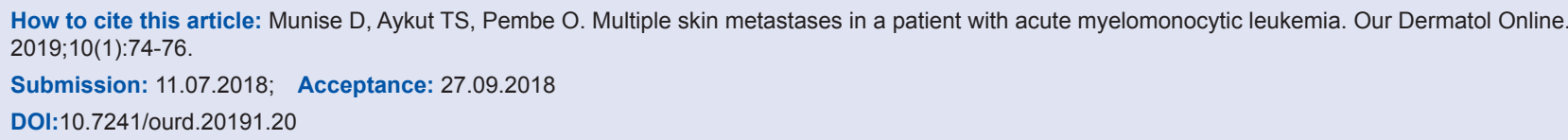




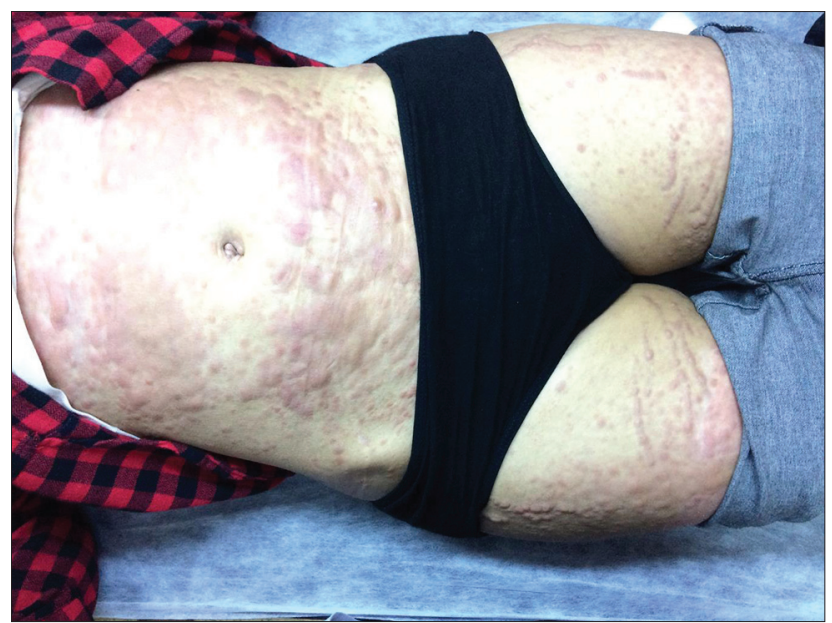

Figure 1: Purple colored infiltrative nodular lesions on the whole body.

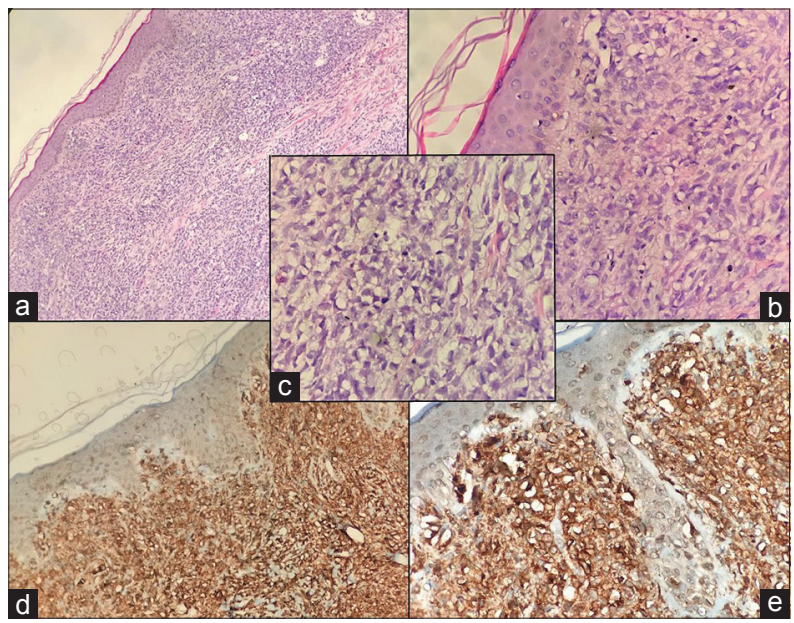

Figure 2: (a)X10, H\&E. (b)X20, H\&E. (c)X40, H\&E; papillary and reticular dermis are seen as infiltrating with atypical blastic cells. (d)X20, LCA (leukocyte common antigen). (e)X40, CD33; immunocytochemically, blastic cells were positive with LCA and CD33.

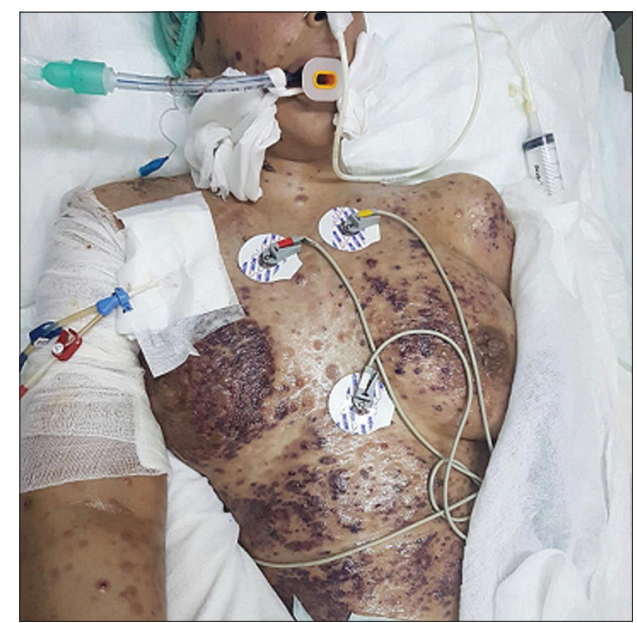

Figure 3: Hemorrhagic infiltrative nodular lesions on the whole body.

In the present case, sepsis was considered by hematology, the patient was hospitalized. The patient was admitted to intensive care unit and the multiple skin metastases were found to be hemorrhagic (Fig. 3). The patient died within one week due to sepsis in the intensive care unit. Informed consent was obtained from the case for the publication of this case report and images.

Prior to the study, patient gave written consent to the examination and biopsy after having been informed about the procedure.

\section{DISCUSSION}

Cancers of the lung, kidney and gastrointestinal tract in males, breast cancer in females are the most common skin metastases [6]. Clinically, skin metastases are usually seen as nonspecific nodule, zosteriform pattern or carcinoma erysipeloides. More rarely, skin metastases may be seen in neoplastic alopecia, annular erythema and ulcer [7]. Lookingbill et al. have demonstrated that the most common lesion in cutaneous metastasis is the nodule [3]. In our case, multiple nodular lesions were observed throughout the whole body.

Histopathological examination is the most important property in the diagnosis of cutaneous metastases, as it is similar to that of the primary tumor [8]. In our study, histology of the sections showed acute myelomonocytic leukemia.

Most cases of cutaneous metastases are indicative of extensive spreading of the disease and death with worse prognosis [9]. The factor that influences the survival is the time elapsed between diagnosis and the occurrence of the cutaneous metastases. The treatment for most patients is palliative, and although chemotherapy and radiotherapy are frequently used in these patients, they are inconclusive in many cases [10].

Skin metastases can lead to a diagnosis of primary unknown cancer. However, skin metastases usually occur during the course of an existing cancer [11]. The presence of skin metastases is important in terms of showing the failure of treatment with cancer. When skin metastases are the first distant metastases, recognition of it is of great importance in terms of treatment change [12]. In our case, skin metastasis was the first metastasis detected.

Leukemia cutis (LC) is a condition presenting various cutaneous lesions such as papules, macules, plaques, nodules, ecchymoses, palpable purpura and ulcerative lesions, which are formed by skin invasion of neoplastic 
cells [13]. Survive from diagnosis of leukaemia cutis to death ranged from 3 to 24 months. In 13\% of LC cases, the underlying disease is AML, most commonly in the monocytic subtype of AML [14]. So in our case, Acute myelomonocytic leukemia was present.

Leukemia cutis lesions are generally localized, and can influence any part of the body. Along with being variable in the studies, it has been reported that the most common affected region is the trunk [15]. In our case it was interesting to find that AML M4 skin involvement is widespread. In the literature, there were no cases as wide as skin involvement of our case.

\section{CONCLUSION}

Leukemia cutis is an uncommon condition, its occurrence entails worse prognosis, as it is corporated with disease progression and survival reduce in these patients. We wanted to note that leukemia cutis should not be forgotten in the differential diagnosis of nodular skin lesions.

\section{Consent}

The examination of the patient was conducted according to the Declaration of Helsinki principles.

\section{REFERENCES}

1. Chopra R, Chhabra S, Samra SG, Thami GP, Punia RP, Mohan H. Cutaneous metastases of internal malignancies: a clinicopathologic study. Indian J Dermatol Venereol Leprol. 2010;76:125-31.

2. Song Z, Lin B, Shao L, Zhang Y. Cutaneous metastasis as a initial presentation in advanced non-small cell lung cancer and its poor survival prognosis. J Cancer Res Clin Oncol. 2012;138:1613-7.

3. Lookingbill DP, Spangler N, Helm KF. Cutaneous metastases in patients with metastatic carcinoma: a retrospective study of 4020 patients. J Am Acad Dermatol. 1993;29(2):228-36.

4. Douet-Guilbert N, Chauveau A, Gueganic N, Guillerm G, Tous C,
Le Bris MJ, et al. Acute myeloid leukaemia (FAB AML-M4Eo) with cryptic insertion of $\mathrm{cbfb}$ resulting in cbfb-Myh11 fusion. Hematol Oncol. 2017;35:385-9.

5. Martínez-Leboráns L, Victoria-Martínez AM, TorregrosaCalatayud JL, de Miquel VA. Leucemia cutis. Serie de 17 casos y revisión de la literatura. Actas Dermo-Sifiliograf. 2016;107:e65-9.

6. Alcaraz I, Cerroni L, Ruetten A, Kutzner H, Requena L. Cutaneous metastases from internal malignancies: a clinicopathologic and immunohistochemical review. The Am J Dermatopathol. 2012;34:347-93.

7. Wong CYB, Helm MA, Kalb RE, Helm TN, Zeitouni NC. The presentation, pathology, and current management strategies of cutaneous metastasis. North Am J Med Scien. 2013;5:499.

8. Kanyilmaz G, Aktan M, Koc M, Findik S. Cutaneous metastases of the synchronous primary endometrial and bilateral ovarian cancer: an infrequent presentation and literature review. Case Rep Oncol Med. 2016;2016:4568653.

9. Wick MR. Primary Lesions That May Imitate metastatic tumors histologically: A selective review. Semin Diagn Pathol. 2018;35:123-42.

10. Leonard R, Hardy J, Van Tienhoven G, Houston S, Simmonds P, David M, et al. Randomized, double-blind, placebo-controlled, multicenter trial of $6 \%$ miltefosine solution, a topical chemotherapy in cutaneous metastases from breast cancer. J Clin Oncol. 2001;19:4150-9.

11. Kara A, Belli AA, Alatas ET, Tanriverdi O, Dere Y. Widespread cutaneous metastasis from ovarian serous adenocarcinoma. Dermatol Online J. 2016;22:pii:13030/qt9mx8r32z.

12. Atış G, Tükenmez Demirci G, Kıvanç Atunay İ, Sakız D. The clinical characteristics and the frequency of metastatic cutaneous tumors among primary skin tumors. Turkderm. 2013;47:166-9.

13. Cronin DM, George TI, Reichard KK, Sundram UN. Immunophenotypic analysis of myeloperoxidase-negative leukemia cutis and blastic plasmacytoid dendritic cell neoplasm. Am J Clin Pathol. 2012;137:367-6.

14. Kang YS, Kim HS, Park HJ, Lee JY, Kim HO, Cho BK, et al. Clinical characteristics of 75 patients with leukemia cutis. J Korean Med Scien. 2013;28:614-9.

15. Peña-Romero AG, Domínguez-Cherit J, Méndez-Flores S. Leukemia cutis: clinical features of 27 Mexican patients and a review of the literature. Gac Med Mex. 2016;152:629-35.

Copyright by Daye Munise, et al. This is an open-access article distributed under the terms of the Creative Commons Attribution License, which permits unrestricted use, distribution, and reproduction in any medium, provided the original author and source are credited.

Source of Support: Nil, Conflict of Interest: None declared. 